\title{
Membrane Inlet Mass Spectrometry for Homeland Security and Forensic Applications
}

\author{
Stamatios Giannoukos, ${ }^{1}$ Boris Brkić, ${ }^{1}$ Stephen Taylor, ${ }^{1}$ Neil France ${ }^{2}$ \\ ${ }^{1}$ Department of Electrical Engineering and Electronics, University of Liverpool, Liverpool, L69 3GJ, UK \\ ${ }^{2} \mathrm{Q}$ Technologies Ltd., Liverpool, L15 6UX, UK
}

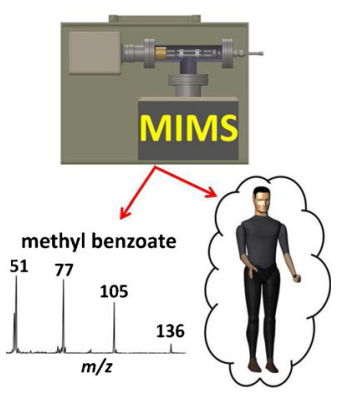

\begin{abstract}
A man-portable membrane inlet mass spectrometer has been built and tested to detect and monitor characteristic odors emitted from the human body and also from threat substances. In each case, a heated membrane sampling probe was used. During human scent monitoring experiments, data were obtained for inorganic gases and volatile organic compounds emitted from human breath and sweat in a confined space. Volatile emissions were detected from the human body at low ppb concentrations. Experiments with compounds associated with narcotics, explosives, and chemical warfare agents were conducted for a range of membrane types. Test compounds included methyl benzoate (odor signature of cocaine), piperidine (precursor in clandestine phencyclidine manufacturing processes), 2-nitrotoluene (break-
\end{abstract} down product of TNT), cyclohexanone (volatile signature of plastic explosives), dimethyl methylphosphonate (used in sarin and soman nerve agent production), and 2-chloroethyl ethyl sulfide (simulant compound for sulfur mustard gas). Gas phase calibration experiments were performed allowing sub-ppb LOD to be established. The results showed excellent linearity versus concentration and rapid membrane response times.

Keywords: Homeland security, Membrane inlet mass spectrometry, Threat odors, Drugs, Explosives, CWAs

Received: 22 August 2014/Revised: 20 October 2014/Accepted: 21 October 2014/Published Online: 15 November 2014

\section{Introduction}

$\mathrm{F}$ requently, customs agencies and border protection authorities address issues related to national security such as illegal human trafficking and illicit transportation of restricted or harmful substances [1].

Human chemical signatures mainly describe the odor signals released from the human body [2]. These odors may be used to discriminate individuals and also to define their physical condition or emotional status [3]. VOCs emitted from exhaled breath, sweat, and other biological secretions carry unique and very often pivotal information-data for each individual and are correlated with daily habits (diet, smoking (or not), exercise, medication, etc.), ethnic background, gender, age, living and working environments, etc. [4-10]. During the last few years, human body VOC emissions have been a live topic in many fields, such as in medicine as potential disease or disorder biomarkers [11],

Electronic supplementary material The online version of this article (doi:10.1007/s13361-014-1032-7) contains supplementary material, which is available to authorized users.

Correspondence to: Stephen Taylor; e-mail: s.taylor@liv.ac.uk in search and rescue operations as tools for the early detection of entrapped people in the debris of collapsed buildings [12,13], in homeland security applications as indicators of illegal human presence in confined areas [14], or even as markers of buried human bodies in forensic investigations [15].

Human breathing is a dynamic process, releasing a complex mixture of inorganic gases and hundreds traces of VOCs. Most of the VOCs (even their endogenous or exogenous origin) in breath have typical concentration ranges at $\mathrm{ppb}$ or ppt concentration levels and are responsible for human breath odor. Endogenous breath volatile compounds describe internal metabolic processes, whereas exogenous VOCs originate from environmental or external man-caused exposures or contaminations [16]. Qualitative and quantitative work on exhaled breath VOC emissions has been previously carried out, but this still needs further investigation and exploration, including larger sample groups under different experimental conditions and criteria. Characteristically, previous work for breath compounds gives median concentrations, for ammonia: $833 \mathrm{ppb}$, for acetone: $477 \mathrm{ppb}$, for isoprene: $106 \mathrm{ppb}$, for methanol: $461 \mathrm{ppb}$, for ethanol: $112 \mathrm{ppb}$, and for acetaldehyde and propanol: $22 \mathrm{ppb}$ and $18 \mathrm{ppb}$, respectively [17-21]. 
Human skin is the largest human organ with a complex structure comprising glands distributed variously across the body area [22]. It is divided into two layers: the outer (epidermis) and the inner (dermis), which mainly contains the majority of the glands. These glands can be grouped in three major categories: eccrine (mainly contain water, salt, amino acids, sugars, lactic acid, and glycoproteins), sebaceous (mostly include lipids), and apocrine glands (consist of water, proteins, and lipids) [23]. The complicated gland allocation system delivers different compositions of secretions among different body regions and subsequently different chemical profiles with dissimilar density levels. For example, axillae present a high density of sebaceous glands, soles have a high density of eccrine glands, whereas arms and legs appear to have a low density of eccrine and sebaceous glands. Gland secretions (primarily sterile and odorless liquids) interact with skin hosted microbiota (e.g., aerobic or anaerobic bacteria, etc.) and through various complex metabolic processes result in the production of the odorous sweat. Numerous studies have confirmed that the characteristic human sweat odor comprises $\mathrm{C}_{6}$ to $\mathrm{C}_{11}$ normal, branched-chain, and unsaturated aliphatic acids, carbonyls, ketones, alcohols, aldehydes, amines, and some steroids [22, 23].

Existing technology available in the market for laboratory analysis of human body VOCs mainly utilize mass spectrometry-based techniques. Most popular methodologies include gas chromatography coupled with mass spectrometry (GC-MS) [2], proton transfer reaction mass spectrometry (PTR-MS) [24], selected ion flow tube mass spectrometry (SIFT-MS) [17-20], and ion mobility spectrometry (IMS) [25]. Electronic noses [26] as intelligent chemical sensor array systems and laser spectroscopy [27] have also been applied in real-time measurements for breath and sweat analysis.

Situations such as illegal transportation of restricted goods (drugs, explosives, chemical weapons) as well as the associated with them precursor or breakdown compounds threaten public safety. Their very low vapor pressure values render their detection particularly difficult [28]. Recent developments in analytical instrumentation and in sample introduction procedures allow selective, rapid threat detection and on-line monitoring. Nevertheless, improvements on man-portable, field-deployable, or standoff devices are still needed. The most important technologies for threat detection can be summarized as follows: spectrometry (mass spectrometry (MS) [29], ion mobility spectrometry (IMS) [25]), optical methods, terahertz (THz) [30], infra-red (IR) [31], X-radiation [32], laser spectroscopy, light detection and ranging (LIDAR), cavity ring down spectroscopy (CRDS), Raman [8], electronic noses (EN) [33], sensors (chemical, immunochemical, electrochemical, and fiber-optic) and nanotechnology (e.g., nanoparticles or nanotubes)-based techniques [8].

Mass spectrometry constitutes a powerful instrumental method for chemical analysis, offering accurate and rapid analysis both in the lab and in situ. Progress in miniaturization of individual MS parts has allowed an integrated system approach ideal for in-field operation. In comparison with other analytical techniques (usually large bulky systems) for threat substance detection, MS offers trace analysis (down to ppt levels) with high precision. Membrane introduction mass spectrometry (MIMS) $[34,35]$ is a type of MS that utilizes a membrane sampling probe to allow selective permeation of molecules in the gaseous or aqueous phase [36, 37] into the device and thus their further qualitative and quantitative analysis. It offers reliable analysis, accuracy, robustness, fast response times (within some seconds), and provides low limits of detection (down to low ppt concentration levels) at low cost. Membrane material, structure, and porosity play important roles in the whole analytical procedure [38-40]. Because MIMS as a technique does not require prior sample preparation, it is ideal for portable MS systems and for on-site applications [41].

Field chemical analysis in harsh environments such as border checkpoints has certain difficulties in comparison with laboratory analysis. For homeland security applications, the limitations include variable chemical environmental background profiles (stable or dynamic), which are dependent on weather conditions (e.g., temperature, humidity, wind direction, and wind velocity), materials that may interfere with human body VOCs or with threat compound vapor plumes (e.g., odor emissions from passenger's personal belongings), surface absorption phenomena, indoor air quality, or even air pollution. Moreover, human body VOCs or threat "odorprints" usually have very weak intensity signals (e.g., ppb or ppt concentration levels). Obviously, the distance between the threat source and the sampling point of the MIMS plays an important role in the detection process and speed. This paper

Table 1. Summary of the Simulant Compounds Used in the MIMS Tests

\begin{tabular}{|c|c|c|c|c|c|c|c|c|}
\hline Substance & Parent compound & $\begin{array}{l}\text { Molecular } \\
\text { weight } \\
(\mathrm{g} / \mathrm{mol})\end{array}$ & $\begin{array}{l}\text { Vapor pressure } \\
\text { (Torr) at } 20^{\circ} \mathrm{C}\end{array}$ & $\begin{array}{l}\text { Boiling point } \\
\left({ }^{\circ} \mathrm{C}\right)\end{array}$ & Simulant compound & $\begin{array}{l}\text { Molecular } \\
\text { weight } \\
(\mathrm{g} / \mathrm{mol})\end{array}$ & $\begin{array}{l}\text { Vapor pressure } \\
\text { (Torr) at } 20^{\circ} \mathrm{C}\end{array}$ & $\begin{array}{l}\text { Boiling } \\
\text { point } \\
\left({ }^{\circ} \mathrm{C}\right)\end{array}$ \\
\hline \multirow[t]{2}{*}{ Drug } & Cocaine & 303.353 & $\sim 10^{-8}$ & 187 & Methyl benzoate & 136.147 & 0.28 & 199.6 \\
\hline & Phencyclidine & 243.387 & N.A. & 136 & Piperidine & 85.147 & 23 & 106 \\
\hline \multirow[t]{2}{*}{ Explosive } & TNT & 227.131 & $6.71 * 10^{-6}$ & 240 & 2-Nitrotoluene & 137.136 & 0.1 & 221.7 \\
\hline & $\mathrm{C} 4$ & N.A. & N.A. & 234 & Cyclohexanone & 98.143 & 3.4 & 155.6 \\
\hline \multirow[t]{3}{*}{ CWA } & Sarin (GB) & 140.093 & 2.10 & 158 & Dimethyl methylphosphonate & 124.075 & $<0.6$ & 181 \\
\hline & Soman (GD) & 182.172 & 0.40 & 198 & (DMMP) & & & \\
\hline & Sulfur mustard & 159.077 & 0.069 & 218 & $\begin{array}{l}\text { 2-Chloroethyl ethyl } \\
\text { sulphide (CES) }\end{array}$ & 124.632 & 3.4 & 156 \\
\hline
\end{tabular}


Table 2. Summary of Participants' Phenotype

\begin{tabular}{llllll}
\hline Ref. no & Gender & Age (y) & Mass $(\mathrm{kg})$ & $\begin{array}{l}\text { Height } \\
(\mathrm{cm})\end{array}$ & $\begin{array}{l}\text { Ethnic } \\
\text { background }\end{array}$ \\
\hline 1 & Male & 25 & 75 & 177 & White European \\
2 & Male & 22 & 84 & 190 & White European \\
3 & Male & 23 & 75 & 179 & White European \\
\hline
\end{tabular}

reports the use of a portable MIMS system weighing less than $18 \mathrm{~kg}$ for monitoring male human chemical signatures and odor signatures emitted from threat or hazardous substances.

\section{Experimental}

In order to detect characteristic human scents and to build the chemical profile of human presence in an enclosed area, human confinement in a shipping container was simulated. For our tests, a small room $(3.37 \mathrm{~m} \times 5.00 \mathrm{~m} \times 2.50 \mathrm{~m})$ was used to simulate a small size standard container similar to those used by cargo services. For the smooth completion of the tests, three young (under the age of $30 \mathrm{y}$ ) male participants were recruited and agreed to voluntary follow some experimental rules. Personal preparation guidance rules included some food diet and hygiene restrictions. During the sampling process, the volunteers were asked to follow a 6-h protocol allowing their body scent to fill the container simulator. Volatile emissions from human sweat, skin, and exhaled breath were monitored during the time with a heated membrane sampling probe coupled to a triple filter quadrupole mass spectrometer.

Monitoring of odor signatures emitted from illegal or even hazardous for human life substances such as narcotics, bombs, and chemical weapons formed the second subtask of this work. Drug simulant compounds selected to be examined and simulate the real illicit compounds included methyl benzoate (characteristic odorous signature of cocaine) and piperidine (closely associated with phencyclidine). Explosive simulants that were tested includeed 2-nitrotoluene (intermediate component in the synthesis of explosives and breakdown product of TNT) and cyclohexanone (most abundant compound found in the headspace area of $\mathrm{C} 4$ and other plastic explosives). In order to emulate chemical weapons, the following simulant compounds were chosen: dimethyl methylphosphonate (DMMP) that is used in sarin and soman nerve agent production and 2-chloroethyl ethyl sulfide (CES) as simulant for sulfur mustard gas. Experimental trials were replicated three times to ensure repeatability and consistency of the results. Table 1 gives an overview of the targeted compounds tested and their associated parent components as well as selected properties such as vapor pressure and boiling point values.

\section{Human Subjects}

Three young, healthy male volunteers were recruited to participate in the experiments. The diluted volatile odorous emissions

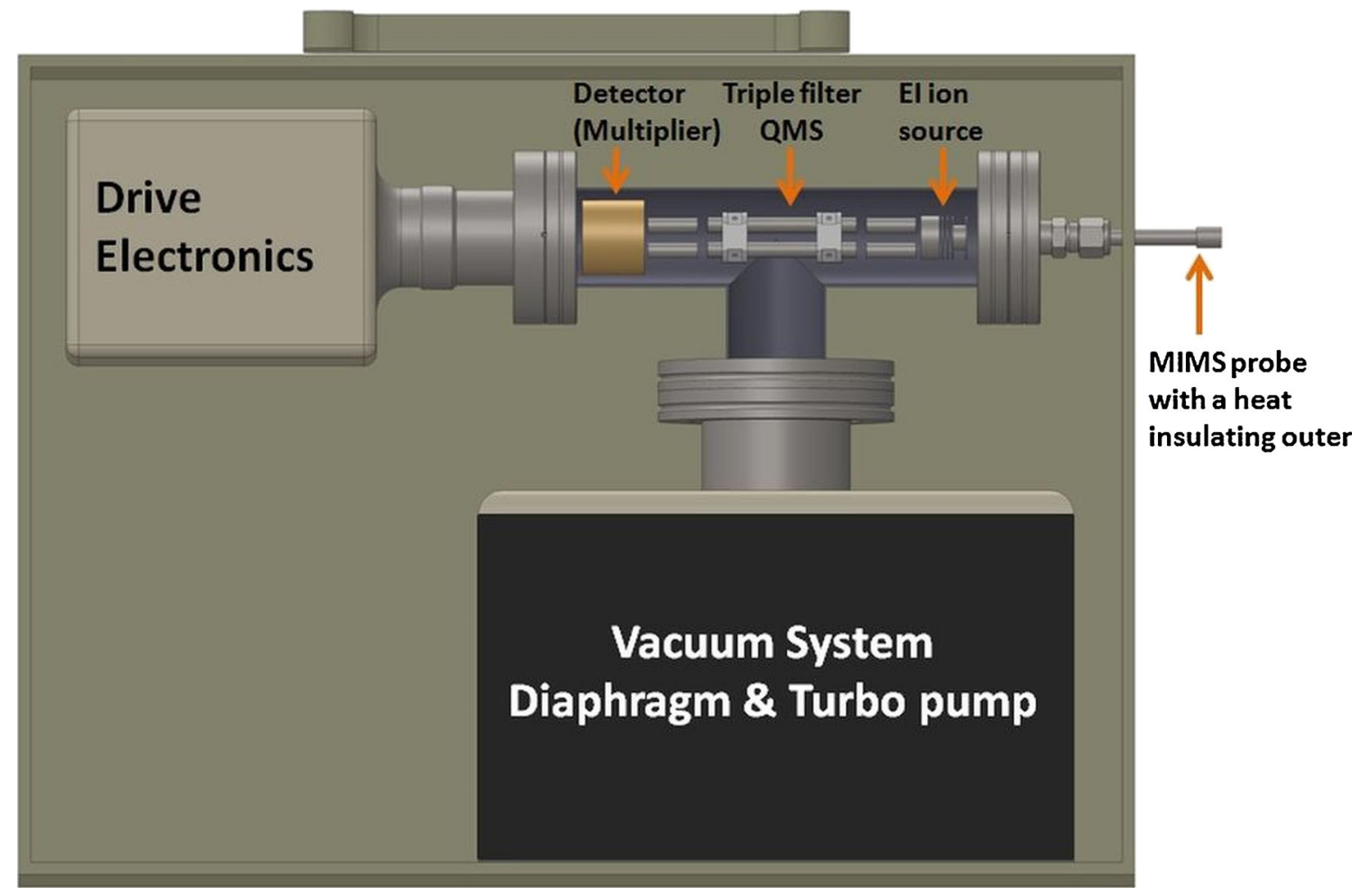

Figure 1. Schematic of the portable MIMS system used for monitoring characteristic chemical odor signatures emitted from human body, drugs, explosives, and CWAs (adapted from Reference [14]) 
(exhaled breath and skin VOCs) of the participants in the container's air were monitored continuously throughout the scheduled experimental day in a systematic way (10 full mass spectra $(m / z 1-200)$ per $\mathrm{h})$ for $6 \mathrm{~h}$. Table 2 summarizes volunteers' phenotypes. This study was approved by the Ethics Committee of the University of Liverpool (ref. no. RETH000650).

\section{Chemicals}

Methyl benzoate (99\%) was obtained from Fisher Scientific Ltd., UK All the other chemicals were bought from Sigma Aldrich Co. LLC., UK at the following purities: piperidine (99\%), 2-nitrotoluene ( $\geq 99 \%)$, cyclohexanone ( $\geq 99 \%)$, dimethyl methylphosphonate (97\%), 2-chloroethyl ethyl sulfide (98\%), and methanol (99.93\%). All purchased chemicals were in the liquid phase.

\section{Test Environment and Experimental Setup}

The experimental series for (1) monitoring and profiling human volatile emissions and (2) monitoring odor markers emitted from threat substances using a MIMS system were performed in the facilities of the University of Liverpool, UK.

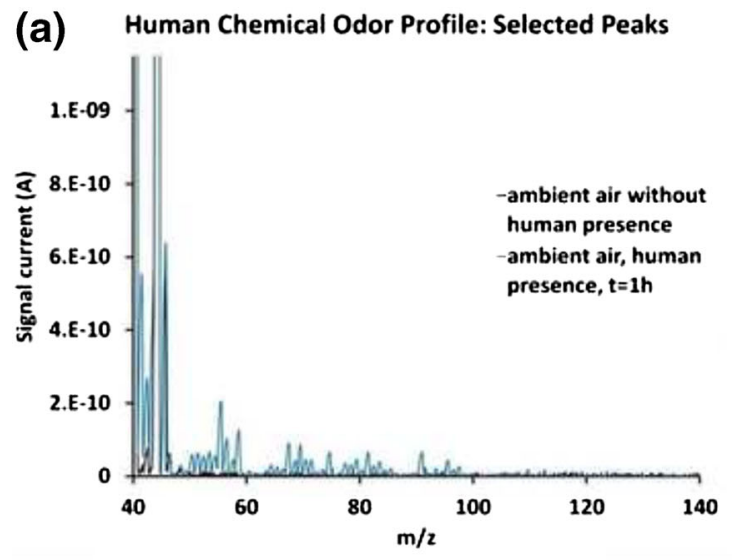

(c) Multiple human experiments: Selected Peaks

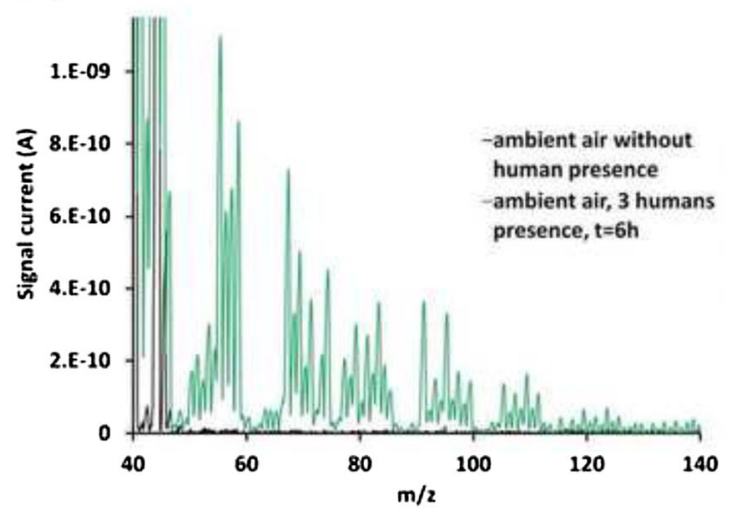

For human chemical signatures monitoring, a small room with similar size to a shipping container was used. The test room was properly cleansed and ventilated prior to the start of the experiments. In order to avoid and/or to eliminate background interferences during measurements, potential odorous sources were removed. Background mass spectra of the simulator's ambient air using the MIMS system were taken systematically before the start date of the experiments as well as one blank measurement was recorded and examined every morning before the start of the experimental process to ensure absence of exogenous analytes. The temperature of the simulator (test room) was approximately $25^{\circ} \mathrm{C}$ and the ambient air did not change throughout the experimental period.

The main parts of Liverpool portable MIMS are: (a) the membrane sampling probe that allows to the gas samples to pass through the membrane and enter into the MS for analysis, (b) the QMS (consisting of an ion source, mass analyzer and detector), (c) the vacuum system (diaphragm and turbomolecular pump), and (d) a laptop computer for data acquisition and interpretation. Figure 1 shows a schematic for the Liverpool MIMS experimental setup that was built specifically for illegal substances detection and on-line monitoring.

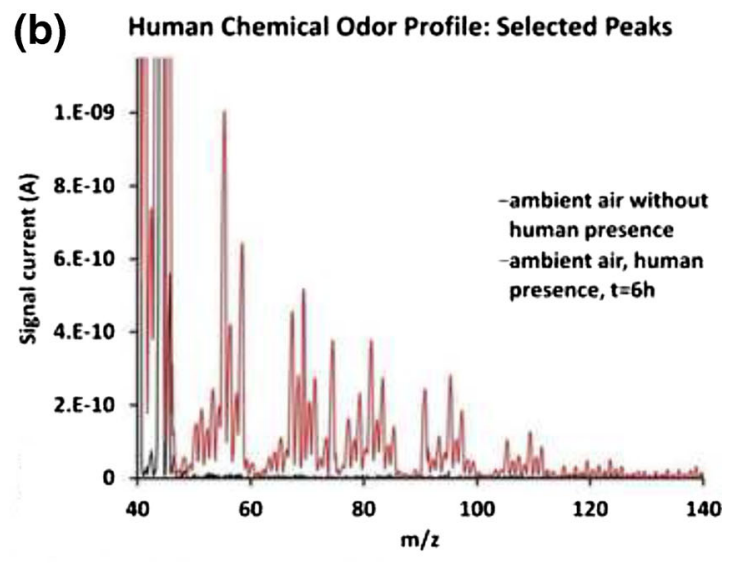

\section{(d) Characteristic human body odorous compounds}

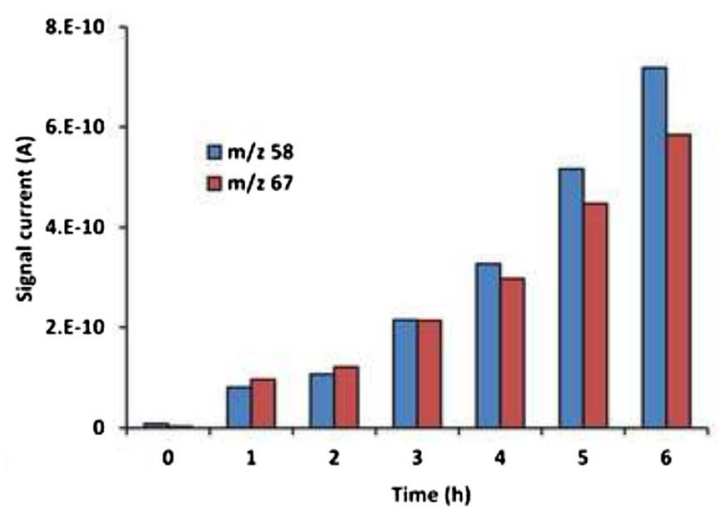

Figure 2. Comparative presentation of mass spectra obtained from the ambient air of the container simulator (a) without and with human presence after $1 \mathrm{~h}$, (b) without and with human presence after $6 \mathrm{~h}$, (c) without and with multiple human presence after $6 \mathrm{~h}$, and (d) peak change for acetone $(\mathrm{m} / \mathrm{z} 58)$ and isoprene $(\mathrm{m} / \mathrm{z} 67)$ during multiple human experiments 

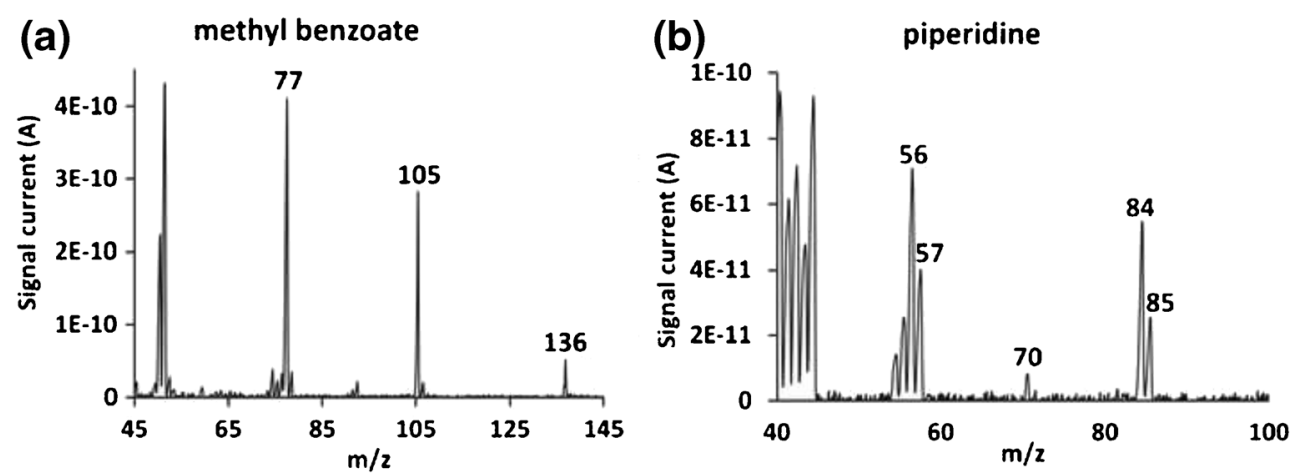

Figure 3. Representative experimental drug simulant mass spectra at 50 ppb for (a) methyl benzoate and (b) piperidine using the Liverpool portable MIMS system

\section{Sample Preparation}

During MIMS tests with threat simulant compounds, gaseous standards of the targeted components were used to confirm their detection and on-line monitoring. In a next experimental level, gas standards were used to evaluate the performance of our MIMS system by producing linear calibration plots. The procedure that was followed for gas standards production was previously described by McClennen et al. [42] and by Naganowska-Nowak et al. [43]. Liquid stock standard solutions of the examined compounds were prepared by volumetric serial dilution in methanol at concentrations of $1000 \mathrm{ppm}$ and $100 \mathrm{ppm}$. Appropriate quantities of the stock solutions were injected with a high precision micro-pipetter (Brand $\mathrm{GmbH}$, Wertheim, Germany) in $1.1 \mathrm{~L}, 2.8 \mathrm{~L}$, and $10 \mathrm{~L}$ narrow-neck glass flasks (Sigma Aldrich Co. LLC., Dorset, UK) filled with atmospheric air, carefully covered, and left for $3 \mathrm{~h}$ at room temperature $\left(25^{\circ} \mathrm{C}\right)$ to evaporate and reach thermodynamic equilibrium. The flask tops were covered with several layers of parafilm $M$ wrapping film. Gaseous standards of (a) methyl benzoate, (b) piperidine, (c) 2-nitrotoluene, (d) cyclohexanone, (e) DMMP, and (f) CES were prepared at the following concentrations: blank, 1, 5, 10, 25, 50, and $100 \mathrm{ppb}$.

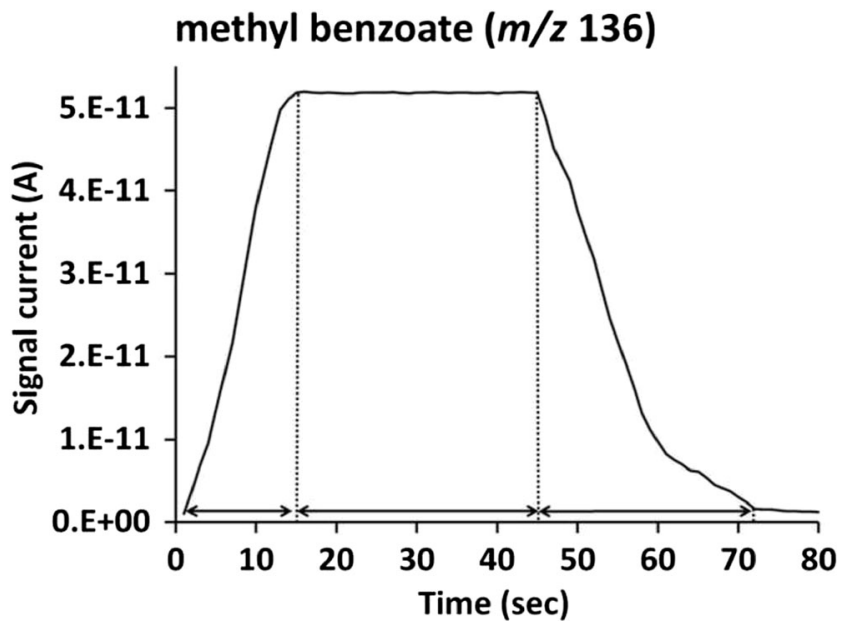

Figure 4. Typical rise and fall response profile for mass 136 of methyl benzoate at $50 \mathrm{ppb}$ as a function of time
The standard gases were tested with the following sequence: from the lowest concentration level to the highest. This was done to eliminate potential memory effects between distinctive measurements and sample to sample carryover errors. Blank flasks containing only atmospheric air were also prepared in order to examine potential exogenous VOC contaminations of the flasks prior to the start of the experimental series. Moreover, the covered with parafilm flasks containing the prepared gas standards were peripherally (outer surrounding area) tested with the MIMS system before experiments to investigate any volatile leakage through the wrapping film. No leakage was observed.

\section{Sample Introduction and Optimization of the Method}

During experiments, a heated flat polydimethylsiloxane (PDMS) membrane sampling probe connected to the vacuum valve was used to directly sample the prepared gas standards. The membrane probe assembly consisted of $10 \mathrm{~cm}$ stainless steel tubing coupled with a membrane sheet supported on the one end side with a 1/4 inch Swagelok stainless steel vacuum fitting union [14]. The thickness of the non-sterile PDMS membrane sheet was $0.12 \mathrm{~mm}$ and its area measured $32 \mathrm{~mm}^{2}$. PDMS membrane was provided by Technical Products, Inc. (Lawrenceville, GA, USA). The membrane probe assembly was externally heated at $70^{\circ} \mathrm{C}$ using an electrical heating wire controlled by a dual digital PID temperature controller (model: TA4-SNR + K). The temperature of the membrane material was additionally monitored using a digital ATC-800 temperature control unit with temperature measuring range from $-20^{\circ} \mathrm{C}$ to $99^{\circ} \mathrm{C}$ to ensure operational temperature stability. PDMS was the main membrane material used for the experiments but in order to optimize our detection and monitoring methodology, four alternative membrane materials [polypropylene (PP), polyethersulfone (PES), polytetrafluoroethylene (PTFE), nylon] with various porosities and thicknesses were also tested.

\section{Mass Spectral Analysis}

Mass spectral analysis of the gas samples was done using a triple filter quadrupole mass spectrometer (QMS) system 
Table 3. Liverpool MIMS System Performance (Response Times, Linearity, and LOD) with the Examined Drug Simulant Compounds

\begin{tabular}{lllll}
\hline Compound name & $\begin{array}{l}\text { Rise time } \\
(\mathrm{s})\end{array}$ & $\begin{array}{l}\text { Fall time } \\
(\mathrm{s})\end{array}$ & $\mathrm{R}^{2}$ & $\begin{array}{l}\text { LOD } \\
(\mathrm{ppb})\end{array}$ \\
\hline Methyl benzoate $(\mathrm{m} / \mathrm{z} 136)$ & 15 & 27 & 0.9975 & 0.68 \\
Piperidine $(\mathrm{m} / \mathrm{z} 85)$ & 22 & 58 & 0.9994 & 0.96 \\
\hline
\end{tabular}

provided by Q-Technologies Ltd., Liverpool, UK. The portable QMS system consists of an electron impact (EI) ion source at $70 \mathrm{eV}$, the mass analyzer, and the detector. The enclosed EI ion source has a twin Thoria filament assembly with electron emission current value at about $1.60 \mathrm{~mA}$. The mass analyzer contains a pre-filter, a main filter, and a post-filter. The mass range of the analyzer is $m / z 1-200$ with $1 \mathrm{Da}$ resolution throughout the entire mass range. The sensitivity of the mass analyzer is $1.33 \times 10^{-4} \mathrm{~A} /$ Torr. The detector contains a Faraday cup for detecting usual ion currents and a Channeltron type electron multiplier for detecting very low signal currents like those produced from low level concentration VOCs. During data obtainment, 10 acquisition points were recorded per unit mass with average number of 10 scans per measurement throughout the whole mass range. Data were recorded on a laptop computer, interpreted, and compared with reference mass spectra using the NIST Chemistry WebBook as reference database.

\section{Vacuum System}

A stainless steel chamber pumped by a vacuum system consisting of a diaphragm pump (Oerlikon oil-free DIVAC $0.8 \mathrm{~T}$ ) and a turbomolecular pump (TURBOVAC SL 80) purchased from Oerlikon Leybold Vacuum Ltd. (Chessington, UK) was used to host our QMS system. Both pumps provide base pressure down to $7.5 \times 10^{-8}$ Torr. The system pressure was continuously being monitored by a highly accurate digital pressure gauge (model: MPT 100) supplied by Pfeiffer Vacuum Ltd., Newport Pagnell, UK that uses a Pirani/cold cathode method of measurement. The operating pressure during mass analysis with the membrane sampling probe attached and the sample inlet valve fully open varied between $4.0 \times 10^{-6}$ Torr and $2.0 \times 10^{-5}$ Torr.

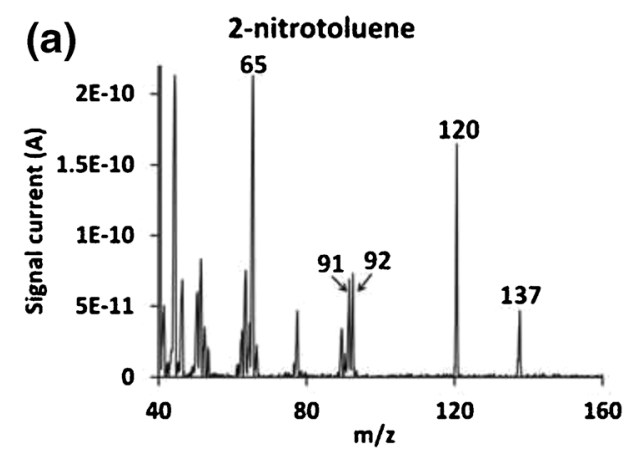

\section{Results and Discussion}

\section{Human Chemical Signatures}

This section describes preliminary results obtained from monitoring of chemical odor signatures emitted by one and three male humans in a confined space (container simulator) throughout a time period of $6 \mathrm{~h}$. Data from a single human volunteer under different experimental conditions have been previously presented elsewhere [14], whereas this work compares new experimental results both for one person and multiple persons in our container simulator. During experiments, VOC emissions from human breath, sweat, skin, and other biological secretions were diluted in the container simulator ambient air. In each test, the human scent plume in the ambient air of the simulator was continuously monitored every hour for $6 \mathrm{~h}$ in total. Figure 2a shows a comparative presentation of mass spectra (with mass range $m / z$ 40-140) obtained from the ambient air of our test chamber without and with human presence after $1 \mathrm{~h}$, whereas acquired data in Figure $2 \mathrm{~b}$ indicate human presence in the container simulator after $6 \mathrm{~h}$ of physical presence. Mass peak intensities after 1 and $6 \mathrm{~h}$ of human enclosure in the container simulator were increased by a factor of five. Figure $2 \mathrm{c}$ refers to multiple human experiments, presenting the chemical profile of the ambient air of the container simulator after $6 \mathrm{~h}$ with three male participants enclosed. Monitoring of inorganic gases, such as $\mathrm{O}_{2}(\mathrm{~m} / \mathrm{z} 32)$ and $\mathrm{CO}_{2}(\mathrm{~m} / \mathrm{z}$ 44), responses are of particular concern in human detection in a confined space. During measurements, oxygen levels slightly decreased over time, remaining though sufficiently high for safe human life. On the other hand, $\mathrm{CO}_{2}$ levels slowly increased during the $6 \mathrm{~h}$ of the experiments (approximately $1.3 \%$ for the single human experiment and $2.4 \%$ for the multiple human experiments). The $\mathrm{CO}_{2}$ signal level in the container simulator was found to be between 20 and 30 times greater than the signals of the VOCs of interest. This is surprising in view of the fact that level of exhaled $\mathrm{CO}_{2}$ is orders of magnitude greater than exhaled VOCs such as acetone and isoprene. We attribute this difference to partition effects in the membrane, and this remains the subject of further work. Organic compounds of interest include acetone $(\mathrm{m} / \mathrm{z} 43,58)$ and isoprene $(\mathrm{m} / \mathrm{z} 67,68)$, as characteristic odor compounds of human

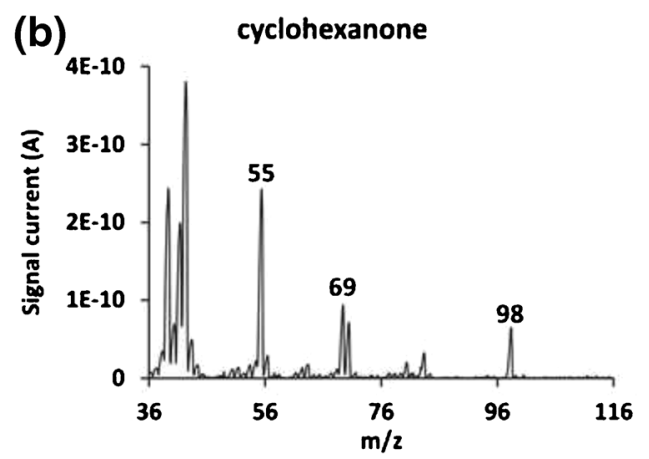

Figure 5. Representative experimental explosive simulant mass spectra at 50 ppb for (a) 2-nitrotoluene, and (b) cyclohexanone using the Liverpool portable MIMS system 
Table 4. Liverpool MIMS System Performance (Response Times, Linearity, and LOD) with the Examined Explosive Simulant Compounds

\begin{tabular}{lllll}
\hline Compound name & $\begin{array}{l}\text { Rise time } \\
(\mathrm{s})\end{array}$ & $\begin{array}{l}\text { Fall time } \\
(\mathrm{s})\end{array}$ & $\mathrm{R}^{2}$ & $\mathrm{LOD}(\mathrm{ppb})$ \\
\hline 2-Nitrotoluene $(\mathrm{m} / \mathrm{z} 137)$ & 18 & 27 & 0.9977 & 0.80 \\
Cyclohexanone $(m / z 98)$ & 10 & 28 & 0.9993 & 0.61 \\
\hline
\end{tabular}

breath and skin, and showed an upward trend throughout the 6 $\mathrm{h}$ experimental duration. From standard concentration measurement experiments, the following concentrations were estimated for the targeted volatile compounds for a male volunteer in the container simulator after $6 \mathrm{~h}$ of enclosure: acetone at 18 $\mathrm{ppb}$ and isoprene at $11 \mathrm{ppb}$. For the three participants, the levels of acetone and isoprene increased compared with the case when one human was confined. Acetone exhibited approximate concentration levels much higher than $20 \mathrm{ppb}$ and isoprene $19 \mathrm{ppb}$. Figure $2 \mathrm{~d}$ presents the peak change for acetone $(\mathrm{m} / \mathrm{z} 58)$ and isoprene $(\mathrm{m} / \mathrm{z} 67)$ as a function of time during multiple human experiments.

\section{Drug Simulants Experiments}

This subsection investigates the mass spectrometric monitoring of methyl benzoate as characteristic odor signature emitted from cocaine molecules and of piperidine as major precursor component in the illegal production of PCP (recreational and dissociative narcotic, widely known as angel dust). Liverpool MIMS system was initially used to examine the ability of a heated at $70^{\circ} \mathrm{C}$ PDMS membrane inlet sampling probe to detect the selected compounds. After confirmation that detection with MIMS was achievable, gas standards of the selected volatile compounds were prepared for on-line monitoring at the following concentration levels: blank, 1, 5, 10, 25, 50, and 100 ppb. Representative mass spectra for methyl benzoate and for piperidine corresponding to $50 \mathrm{ppb}$ gas standards are presented in Figure 3. Calibration plots were generated to evaluate the performance of the method. In order to produce calibration curves, two characteristic mass fragments for each targeted compound were chosen. This was done to confirm that their signal intensities were closely dependent on the gas sample

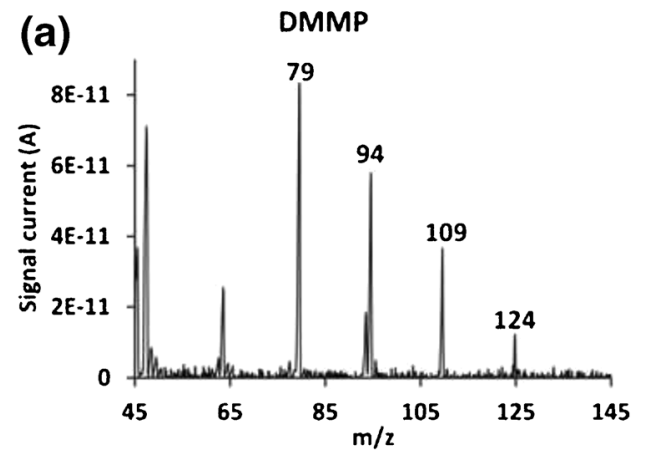

Table 5. Liverpool MIMS System Performance (Response Times, Linearity, and LOD) with the Tested CWA Simulant Compounds

\begin{tabular}{lllll}
\hline Compound name & Rise time $(\mathrm{sec})$ & Fall time $(\mathrm{s})$ & $\mathrm{R}^{2}$ & LOD $(\mathrm{ppb})$ \\
\hline $\operatorname{DMMP}(m / z$ 124) & 14 & 28 & 0.9987 & 0.85 \\
CES $(m / z 124)$ & 12 & 41 & 0.9984 & 0.70 \\
\hline
\end{tabular}

concentrations. Calibration curves of our MIMS instrument for the two drug associated gas standard compounds at the concentration area from 1 to $100 \mathrm{ppb}$ exhibited excellent linearity with the following $\mathrm{R}^{2}$ values: 0.9975 for mass 136 and 0.9972 for mass 105 of methyl benzoate, and 0.9994 for mass 85 and 0.9991 for mass 84 of piperidine. The system response times were in the level of few seconds. Figure 4 presents typical membrane rise and fall response times for mass 136 of methyl benzoate at $50 \mathrm{ppb}$. A stable sampling period with duration $30 \mathrm{~s}$ is also shown. Rise response time represents the time required for the signal intensity to reach its maximum value, whereas fall time shows the time needed for the membrane material to purify and peak signals return to baseline level. Limits of detection (LOD) were calculated (based on signal current comparisons with the $1 \mathrm{ppb}$ mass spectrum) and are shown in Table 3. Detection limits were based on the signal to noise ratio $(\mathrm{S} / \mathrm{N}=3)$. This means that the LOD estimates were calculated so that they will have three times greater signal intensities compared with the baseline (blank/noise) signal levels. Slight differences in mass fragments' relative abundances between reference (NIST Chemistry WebBook) and experimental mass spectra can be explained by the fact that the membrane inlet used in the experiments allows selective permeation of molecules, which depends on molecular structure and on their physical and chemical properties such as polarity, solubility, and vapor pressure.

\section{Explosive Simulants Experiments}

The mass spectral investigation of volatile compounds associated with explosive materials is presented in this subsection. Representative mass spectra for 2-nitrotoluene and cyclohexanone corresponding to $50 \mathrm{ppb}$ gas standards are shown in

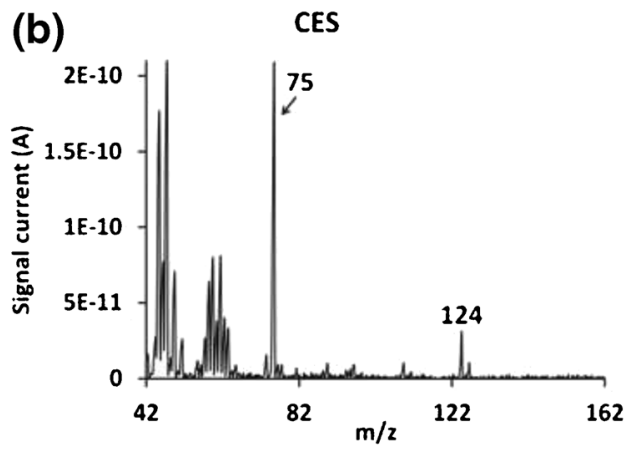

Figure 6. Representative experimental chemical weapon simulant mass spectra at 50 ppb for (a) DMMP, and (b) CES using the Liverpool portable MIMS system 
Figure 5. Gas standards of 2-nitrotoluene and cyclohexanone were prepared for on-line monitoring at the following concentration levels: blank, $1,5,10,25,50$, and 100 ppb. Calibration curves of our MIMS instrument for explosive simulant analytes exhibited excellent linear performance with $\mathrm{R}^{2}$ values of 0.9977 for mass 137 and 0.9972 for mass 120 of 2-nitrotoluene, and 0.9993 for mass 98 and 0.9991 for mass 55 of cyclohexanone, as presented in Table 4. Limits of detection of our technique for the targeted explosive stimulant compounds were calculated (as described in drug stimulants experiments subsection) at high ppt concentration levels.tgroup

\section{Chemical Weapon Simulants Experiments}

The mass spectrometric monitoring of distinctive odor emitted from CWAs is examined in this section. Gas standards of characteristic odorous compounds (DMMP and CES), which simulate chemical weapons, were prepared for on-line monitoring at the following concentration levels: blank, 1, 5, 10, 25, 50 , and $100 \mathrm{ppb}$. Representative mass spectra for DMMP and CES corresponding to $50 \mathrm{ppb}$ gas standards are presented in Figure 6. As shown in Table 5, our MIMS instrument exhibited fast response times and very good linearity for the targeted substances with the following $\mathrm{R}^{2}$ values: 0.9987 for mass 124 and 0.9986 for mass 109 of DMMP, and 0.9984 for mass 124 and 0.9984 for mass 75 of CES.

\section{Conclusions}

A portable membrane inlet mass spectrometer was applied for (1) human chemical signatures and (2) restricted goods odor monitoring. This paper summarizes the usage of MIMS in trace threat detection for homeland security and forensics applications.

VOCs released from exhaled human breath, sweat, and other biological excretes in a container simulator were monitored continuously throughout a time period of $6 \mathrm{~h}$. Experiments took place for one and for three healthy white European male volunteers. Different types of membrane materials, membrane temperatures, and flow rates were examined in order to achieve maximum sensitivity, selectivity, and fast response times. During tests, a plethora of VOCs were detected. Special emphasis was given to inorganic gases (e.g., $\mathrm{O}_{2}$, and $\mathrm{CO}_{2}$ ) and to acetone and isoprene. It was found that a small decrease in $\mathrm{O}_{2}$ abundance levels and increases of the abundances of $\mathrm{CO}_{2}$ and other specific VOCs are indicators of human presence in a container after several hours of enclosure. Further investigation and experimentation, including a larger number of participants with various characteristics and under different scenarios is required.

The same MIMS system was used to monitor characteristic chemical odor signatures emitted from illegal and hazardous components as well as their precursor or breakdown products. Membrane and temperature optimization experiments were also done to achieve optimum system responses. For both experimental series, minimum sample preparation was required. Our portable system was evaluated by addressing essential MIMS analytical criteria such as (a) response times, (b) detection limits, and (c) linear dynamic range [44].

Future work will include field experiments in airports or cargo service facilities with a reduced weight MIMS system and with real threat compounds. The plan is to perform experimental determination of limits of detection in situ and the further evaluation of our apparatus in field conditions. QMS sensitivity and resolution enhancement will be achieved using signal processing software to extract and enhance signals from complex backgrounds and/or from the base (noise) level. This will allow deployment of a smaller, lighter electronic control unit for the QMS and mass range expansion (target $450 \mathrm{Da}$ ).

\section{Acknowledgment}

The research leading to these results has received funding from the European Community's Seventh Framework Programme managed by REA Research Executive Agency (FP7/20072013) under grant agreement no. 285045. The authors thank their project partners TWI Ltd, Aix-Marseille University, Da Vinci Laboratory Solutions, SAES Getters Group, Envisiontec $\mathrm{GbmH}$, Xaar, and Wagtail UK Ltd. The authors gratefully acknowledge Mr. Barry Smith from Q-Technologies Ltd., UK and Dr. Tom Hogan from Pathway Systems Ltd., UK for their technical assistance. Particular acknowledgements are due to Mr. Collin Singer and Ms. Louise Wilson from Wagtail Ltd., UK for their support and for providing facilities and samples pivotal for the development and the progress of the experimental work.

\section{References}

1. U.S. Department of Homeland Security, available at: www.dhs.gov/. Accessed 05 Nov 2014

2. Curran, A.M., Rabin, S.I., Furton, K.G.: Analysis of the uniqueness and persistence of human scent. Forensic Sci. Commun. 7, 1607-1619 (2005)

3. Callagher, M., Wysocki, C.J., Leyden, J.J., Spielman, A.I., Sun, X., Preti, G.: Analyses of volatile organic compounds from human skin. Br. J. Dermatol. 159, 780-791 (2008)

4. Penn, D.J., Oberzaucher, E., Grammer, K., Fischer, G., Soini, H.A., Wiesler, D., Novotny, M.V., Dixon, S.J., Xu, Y., Brereton, R.G.: Individual and gender fingerprints in human body odor. J. R. Soc. Interface 4, 331340 (2007)

5. Kuhn, F., Natsch, A.: Body odor of monozygotic human twins: a common pattern of odorant carboxylic acids released by a bacterial aminoacylase from axilla secretions contributing to an inherited body odor type. J. R. Soc. Interface 6, 377-392 (2009)

6. Haze, S., Gozu, Y., Nakamura, S., Kohno, Y., Sawano, K., Ohta, H., Yamazaki, K.: 2-Nonenal newly found in human body odor tends to increase with aging. J. Invest. Dermatol. 116, 520-524 (2001)

7. Dormont, L., Bessière, J.M., Cohuet, A.: Human skin volatiles: a review. J. Chem. Ecol. 39, 569-578 (2013)

8. Ackerl, K., Atzumuller, A., Grammer, K.: The scent of fear. Neuroendocrinol. Lett. 23, 79-84 (2002)

9. Penn, D., Potts, W.K.: Chemical signals and parasite-mediated sexual selection. Trends Ecol. Evol. 13, 391-396 (1998)

10. Singh, D., Bronstad, P.M.: Female body odor is a potential cue to ovulation. Proc. R. Soc. B 268, 797-801 (2001)

11. Phillips, M., Gleeson, K., Hughes, J.M., Greenberg, J., Cataneo, R.N., Baker, L., McVay, W.P.: Volatile organic compounds in breath as markers of lung cancer: a cross-sectional study. Lancet 353, 1930-1933 (1999) 
12. Huo, R., Agapiou, A., Bocos-Bintintan, V., Brown, L.J., Burns, C., Creaser, C.S., Devenport, N.A., Gao-Lau, B., Guallar-Hoyas, C., Hildebrand, L., Malkar, A., Martin, H.J., Moll, V.H., Patel, P., Ratiu, A., Reynolds, J.C., Sielemann, S., Slodzynski, R., Statheropoulos, M., Turner, M.A., Vautz, W., Wright, V.E., Thomas, C.L.P.: The trapped human experiment. J. Breath Res. 5, 1-12 (2011)

13. Statheropoulos, M., Sianos, E., Agapiou, A., Georgiadou, A., Pappa, A., Tzamtzis, N., Giotaki, H., Papageorgiou, C., Kolostoumbis, D.J.: Preliminary investigation of using volatile organic compounds from human expired air, blood, and urine for locating entrapped people in earthquakes. Chromatogr. B 822, 112-117 (2005)

14. Giannoukos, S., Brkić, B., Taylor, S., France, N.: Monitoring of human chemical signatures using membrane inlet mass spectrometry. Anal. Chem. 86, 1106-1114 (2014)

15. Statheropoulos, M., Spiliopoulou, C., Agapiou, A.: A study of volatile organic compounds evolved from the decaying human body. Forensic Sci. Int. 153, 147-155 (2005)

16. Phillips, M., Greenberg, J.: Method for the collection and analysis of volatile compounds in the breath. J. Chromatogr. 564, 242-249 (1991)

17. Turner, C., Spanel, P., Smith, D.: A longitudinal study of ammonia, acetone, and propanol in the exhaled breath of 30 subjects using selected ion flow tube mass spectrometry, SIFT-MS. Physiol. Meas. 27, 321-337 (2006)

18. Turner, C., Spanel, P., Smith, D.: A longitudinal study of breath isoprene in healthy volunteers using selected ion flow tube mass spectrometry (SIFTMS). Physiol. Meas. 27, 13-22 (2006)

19. Turner, C., Spanel, P., Smith, D.: A longitudinal study of ethanol and acetaldehyde in the exhaled breath of healthy volunteers using selectedion flow-tube mass spectrometry. Rapid Commun. Mass Spectrom. 20, 6168 (2006)

20. Turner, C., Spanel, P., Smith, D.: A longitudinal study of methanol in the exhaled breath of 30 healthy volunteers using selected ion flow tube mass spectrometry, SIFT-MS. Physiol. Meas. 27, 637-648 (2006)

21. Amann, A., Smith, D.: Noninvasive Diagnosis in Physiology and Medicine, pp 343-357. Elsevier, Amsterdam, NL (2013)

22. Smallegange, R.C., Verhulst, N.O., Takken, W.: Sweaty skin: an invitation to bite? Trends Parasitol. 27, 143-148 (2011)

23. Jacoby, R.B., Brahms, J.C., Ansari, S.A., Mattai, J.: Detection and quantification of apocrine secreted odor-binding protein on intact human axillary skin. Int. J. Cosmetic Sci. 26, 37-46 (2004)

24. Amann, A., Poupart, G., Tesler, S., Ledochowski, M., Schmid, A., Mechtcheriacov, S.: Applications of breath gas analysis in medicine. Int. J. Mass Spectrom. 239, 227-233 (2004)

25. Armenta, S., Alcala, M., Blanco, M.: A review of recent, unconventional applications of ion mobility spectrometry (IMS). Anal. Chim. Acta. 703, 114-123 (2011)

26. Natale, C.D., Macagnano, A., Paolesse, R., Tarizzo, E., Mantini, A., Amico, A.D.: Human skin odor analysis by means of an electronic nose. Sensor. Actuat. B-Chem. 65, 216-219 (2000)

27. Wang, C., Sahay, P.: Breath analysis using laser spectroscopic techniques: breath biomarkers, spectral fingerprints, and detection limits. Sensors 9, $8230-8262$ (2009)
28. Moore, D.S.: Recent advances in trace explosives detection instrumentation. Sens Imaging 8, 9-38 (2007)

29. Ouyang, Z., Noll, R.J., Cooks, R.G.: Handheld miniature ion trap mass spectrometers. Anal. Chem. 81, 2421-2425 (2009)

30. Liu, H.B., Chen, Y., Bastiaans, G.J., Zhang, X.C.: Detection and identification of explosive RDX by $\mathrm{THz}$ diffuse reflection spectroscopy. Opt. Express 14, 415-423 (2006)

31. Oxley, J., Smith, J., Brady, J., Dubnikova, F., Kosloff, R., Zeiri, L., Zeiri, Y.: Raman and infrared fingerprint spectroscopy of peroxide-based explosives. Appl. Spectrosc. 62, 906-915 (2008)

32. Wells, K., Bradley, D.A.: A review of X-ray explosives detection techniques for checked baggage. Appl. Radiat. Isotopes 70, 17291746 (2012)

33. Yinon, J.: Detection of explosives by electronic noses. Anal. Chem. 75, 98 105 (2003)

34. Johnson, R.C., Cooks, R.G., Allen, T.M., Cisper, M.E., Hemberger, P.H.: Membrane introduction mass spectrometry: trends and applications. Mass Spectrom. Rev. 19, 1-37 (2000)

35. Boscaini, E., Alexander, M.L., Prazeller, P., Mark, T.D.: Membrane inlet proton transfer reaction mass spectrometry (MI-PTRMS) for direct measurements of VOCs in water. Int. J. Mass Spectrom. 239, 179-186 (2004)

36. Thompson, A.J., Creba, A.S., Ferguson, R.M., Krogh, E.T., Gill, C.G.: A coaxially heated membrane introduction mass spectrometry interface for the rapid and sensitive on-line measurement of volatile and semi-volatile organic contaminant in air and water at parts-per-trillion levels. Rapid Commun. Mass Spectrom. 13, 2000-2008 (2006)

37. Crisper, M.E., Hemberger, P.H.: The direct analysis of semi-volatile organic compounds by membrane introduction mass spectrometry. Rapid Commun. Mass Spectrom. 11, 1449-1453 (1997)

38. Ketola, R.A., Kotiaho, T., Cisper, M.E., Allen, T.M.: Environmental applications of membrane introduction mass spectrometry. J. Mass Spectrom. 37, 457-476 (2002)

39. Cotte-Rodriguez, I., Handberg, E., Noll, R., Kilgour, D.P.A., Cooks, R.G.: Improved detection of low vapor pressure compounds in air by serial combination of single-sided membrane introduction with fiber introduction mass spectrometry (SS-MIMS-FIMS). Analyst 130, 679-686 (2005)

40. Boscaini, E., Alexander, M.L., Prazeller, P., Mark, T.D.: Investigation of fundamental physical properties of a polydimethylsiloxane (PDMS) membrane using a proton transfer reaction mass spectrometer (PTRMS). Int. J. Mass Spectrom. 239, 179-186 (2004)

41. Brkić, B., France, N., Taylor, S.: Oil-in-water monitoring using membrane inlet mass spectrometry. Anal. Chem. 83, 6230-6236 (2011)

42. McClennen, W.H., Vaughn, C.L., Cole, P.A., Sheya, S.N., Wager, D.J., Mott, T.J., Dworzanski, J.P., Arnold, N.S., Meuzelaar, H.L.C.: Roving GC/ MS: mapping VOC gradients and trends in space and time. Field Anal. Chem. Technol. 1, 109-116 (1996)

43. Naganowska-Nowak, A., Konieczka, P., Przyjazny, A., Namiesnik, J.: Development of techniques of generation of gaseous standard mixtures. Crit. Rev. Anal. Chem. 35, 31-55 (2005)

44. Riter, L.S., Takáts, Z., Cooks, R.G.: Single-sided membrane introduction mass spectrometry for on-line determination of semi-volatile organic compounds in air. Analyst 126, 1980-1984 (2001) 